\title{
Diagnosis of Platelet Function Disorders: A Challenge for Laboratories
}

\author{
Miriam Wagner $^{1}$ Günalp Uzun ${ }^{2}$ Tamam Bakchoul ${ }^{1,2}$ Karina Althaus ${ }^{1,2}$ \\ ${ }^{1}$ Transfusion Medicine, Faculty of Medicine, University of Tübingen, \\ Tübingen, Germany \\ ${ }^{2}$ Centre for Clinical Transfusion Medicine, Tübingen ZKT gGmbH, \\ Tübingen, Germany \\ Address for correspondence Karina Althaus, MD, Transfusion \\ Medicine, Faculty of Medicine, University of Tübingen, Otfried-Müller- \\ Strasse 4 Otfried-Müller Straße 4/1, 72076 Tübingen, Germany \\ (e-mail: karina.althaus@med.uni-tuebingen.de).
}

Hamostaseologie 2022;42:36-45.

\author{
Abstract \\ Keywords \\ - platelet function \\ defect \\ - light transmission \\ aggregometry \\ - inherited platelet \\ disorder \\ - granule defect
}

In patients with normal plasmatic coagulation and bleeding tendency, platelet function defect can be assumed. Congenital platelet function defects are rare. Much more commonly they are acquired. The clinical bleeding tendency of platelet function defects is heterogeneous, which makes diagnostic approaches difficult. During the years, a large variety of tests for morphological phenotyping and functional analysis have been developed. The diagnosis of platelet function defects is based on standardized bleeding assessment tools followed by a profound morphological evaluation of the platelets. Platelet function assays like light transmission aggregation, luminoaggregometry, and impedance aggregometry followed by flow cytometry are commonly used to establish the diagnosis in these patients. Nevertheless, despite great efforts, standardization of these tests is poor and in most cases, quality control is lacking. In addition, these tests are still limited to specialized laboratories. This review summarizes the approaches to morphologic phenotyping and platelet testing in patients with suspected platelet dysfunction, beginning with a standardized bleeding score and ending with flow cytometry testing. The diagnosis of a functional defect requires a good collaboration between the laboratory and the clinician.

\section{Introduction}

Platelets play the key role in primary hemostasis. They promote blood vessel repair and maintain the integrity of the vascular system. Well-balanced complex inhibitory and activating pathways are responsible for platelet activation, granule release, platelet aggregation, and thrombus formation. The perioperative bleeding risk in patients with a platelet function defect is considerably higher than in patients with thrombocytopenia ( 24.8 vs. $13.4 \%$, respectively). ${ }^{1}$ Therefore, the diagnosis of impaired hereditary and acquired platelet function defects is important to stratify perioperative risk correctly and guide perioperative management. Perioperative intake of drugs such as nonsteroidal anti-inflammatory drugs (NSAIDs) affects platelet function and may lead to a clinically relevant bleeding disorder. In addition, other drugs such as antibiotics, cyclic adenosine monophosphate stimulators, phosphodiesterase inhibitors, calcium channel blockers, angiotensin-converting enzyme inhibitors, and angiotensin receptor blockers can induce platelet dysfunction and increase bleeding risk. ${ }^{2}$

The assessment of the platelet function is too complex for routine coagulation laboratories. Platelet function tests are time consuming, poorly standardized, and require lots of experience in the field. External quality control testing is rare and not available for most of the methods. National and international surveys revealed interlaboratory differences, and thus methodical standardization is required..$^{3-6}$

\section{received}

October 18, 2021

accepted after revision

November 17, 2021 (c) 2022. Thieme. All rights reserved. Georg Thieme Verlag KG,

Rüdigerstraße 14,

70469 Stuttgart, Germany
DOI https://doi.org/ 10.1055/a-1700-7036. ISSN 0720-9355. 


\section{Etiology of Platelet Function Defects}

Platelet function defects are a common cause for bleeding tendency. They are often acquired due to drug treatment or procedures, medical conditions, or hematologic diseases. ${ }^{7}$ Also herbal remedies, nutritional supplements, food, and beverages can influence platelet function. ${ }^{8}$ Congenital platelet defects are rare and often misdiagnosed. For example, in patients with thrombocytopenia, the misdiagnosis of immune thrombocytopenia is described in up to $61 \%{ }^{9}$ Functional defects can affect platelet adhesion, activation, or aggregation. Among others, there are receptor defects, granule defects, transcription factor defects, signal transduction defects, cytoskeleton defects, and defects of the phospholipid membrane (-Table 1 ).

\section{Diagnostic Approaches}

\section{Bleeding Scores}

Standardized bleeding risk assessment with bleeding scores is a recommended strategy for the evaluation of patients' bleeding risk before surgery. The most commonly used bleeding score is the International Society of Thrombosis and Hemostasis Bleeding Assessment Tool (ISTH-BAT) bleeding score. ${ }^{10}$ This bleeding score was primarily validated for inherited bleeding disorders with von Willebrand disease platelet function defects and has since also been used for the assessment of bleeding tendency in different patient groups. ${ }^{10,11}$ Nevertheless, its diagnostic value in the perioperative prediction of bleeding risk in patients with only a mild bleeding tendency was low. ${ }^{12,13}$ Koscielny et al introduced a standardized questionnaire concerning bleeding history in combination with laboratory testing and was able to verify impaired hemostasis in $40.8 \%$ of the patients with positive bleeding history. ${ }^{14}$

\section{Blood Count}

Measurement of platelet count in automated cell counters enables a first evaluation. Furthermore, mean platelet volume can discriminate between small and large platelets. Some cell counters also determine the immature platelet fraction, which is a sign of an increased platelet turnover.

\section{Morphological Evaluation of Platelets: Microscopy}

In a May-Grünwald-Giemsa-stained blood smear of EDTAanticoagulated blood, platelet size and morphology can be assessed. Patients suffering from Wiskott-Aldrich syndrome, for example, have small size platelets, whereas patients with Bernard-Soulier syndrome or a myosin-9 (MYH9)-related disease show a low platelet count and giant platelets ( - Fig. 1A-D). MYH9-related diseases also present with inclusion bodies in neutrophils (Döhle-like bodies). Platelet aggregates can be found in a pseudothrombocytopenia as a preanalytic artifact when using EDTA tubes. In $\alpha$ granule diseases, large pale platelets can be observed.

Immunofluorescence microscopy offers the possibility of phenotyping platelets via monoclonal antibodies against receptors, granule markers, and cytoskeletal substances. The major advantage is the necessity of a very small amount of blood for this method ( $3.5 \mathrm{~mL}$ per blood smear). Intravenous blood and capillary blood can be used for the preparation of blood smears. Air-dried blood smears are stained after permeabilization and fixation ( - Fig. 2A-D). This is an effective method to recognize receptor defects such as Glanzmann thrombasthenia or Bernard-Soulier syndrome. In patients with MYH9-related diseases, staining the nonmuscular myosin heavy chain IIA (NMMHCII2A), a cytoskeletal contractile protein, cytoplasmic inclusion bodies within the granulocytes show typical clusters. With this finding, genetic testing is no longer crucial for the diagnosis of MYH9-related disease. ${ }^{15}$ Also alterations in granule content can be visualized. Good morphologic characterization makes an important contribution to the reassessment of the likely pathogenic variants in platelet genes that cause the bleeding tendency in these patients. ${ }^{16}$ A combination of light microscopy and immunofluorescence microscopy allows the diagnosis of the underlying cause of inherited platelet disorders in up to $30 \%$ of patients with a suspected inherited platelet disorder. ${ }^{17}$

\section{In Vivo Bleeding Time}

The bleeding time (BT) was first described by Duke and coworkers and later standardized by Ivy et al to assess the platelet function as the first step of primary hemostasis. After a defined skin puncturing on the forearm with a back pressure of $40 \mathrm{~mm} \mathrm{Hg}$, bleeding was noted every 30 seconds with filter paper strips, without touching the wound edges until no more blood stained the filter paper. ${ }^{18}$ In previous studies, BT showed a low predictive value for perioperative bleeding in unselected patients, but in another study, it seemed useful to predict bleeding in patients with positive bleeding history. ${ }^{19,20}$ In patients with recent intake of NSAIDs such as aspirin, BT was not recommended as a reliable method to identify the corresponding defects. ${ }^{19}$ Due to poor standardization, BT cannot be recommended in routine assessment.

\section{In Vitro Bleeding Time}

The in vitro equivalent to the in vivo BT is the platelet function analyzer-200 (PFA-200 [Siemens Healthcare $\mathrm{GmbH}$, Erlangen Germany]). It allows for a quantitative measurement of the primary platelet-derived hemostasis at higher shear stress. ${ }^{21}$ Briefly, citrated whole blood is led through a capillary toward the aperture of a collagen adenosine diphosphate (ADP) or collagen epinephrine-coated membrane system. As it is a von Willebrand factor-dependent method, it is suitable for the detection of mild to severe von Willebrand syndrome, but it has a low sensitivity for mild platelet function defects and storage pool defects. ${ }^{22,23}$ In addition, this method is not reliable in patients with a low platelet count $\left(<100 \times 10^{9} / \mathrm{L}\right)$ and/or a low hematocrit $(<30 \%)$. Due to low sensitivity, it is not recommended by the ISTH for the diagnosis of platelet function defects. ${ }^{24}$

\section{Viscoelastometry}

The viscoelastometry is a well-established method for the detection of trauma-induced coagulopathy. The thromboelastography 


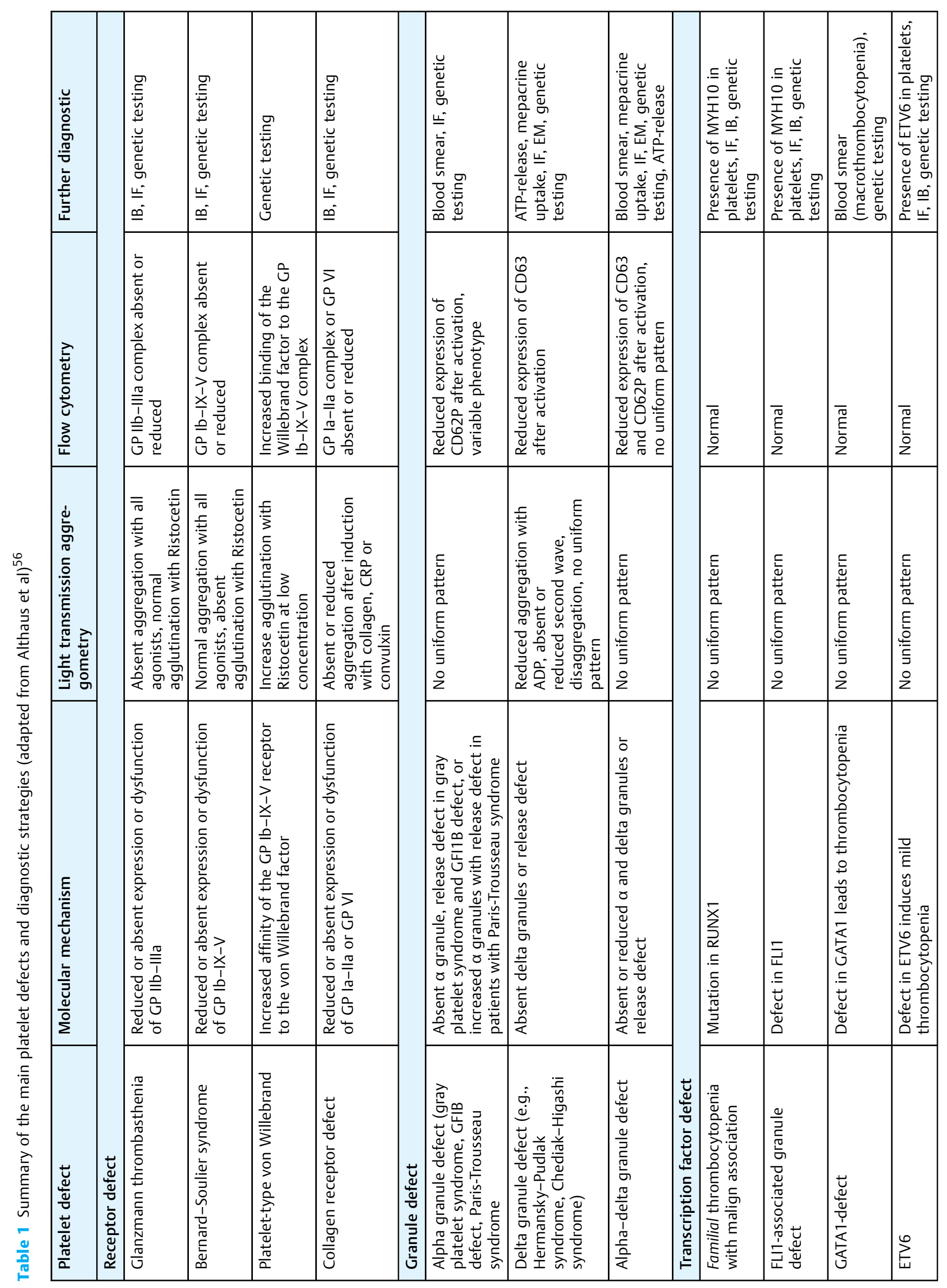




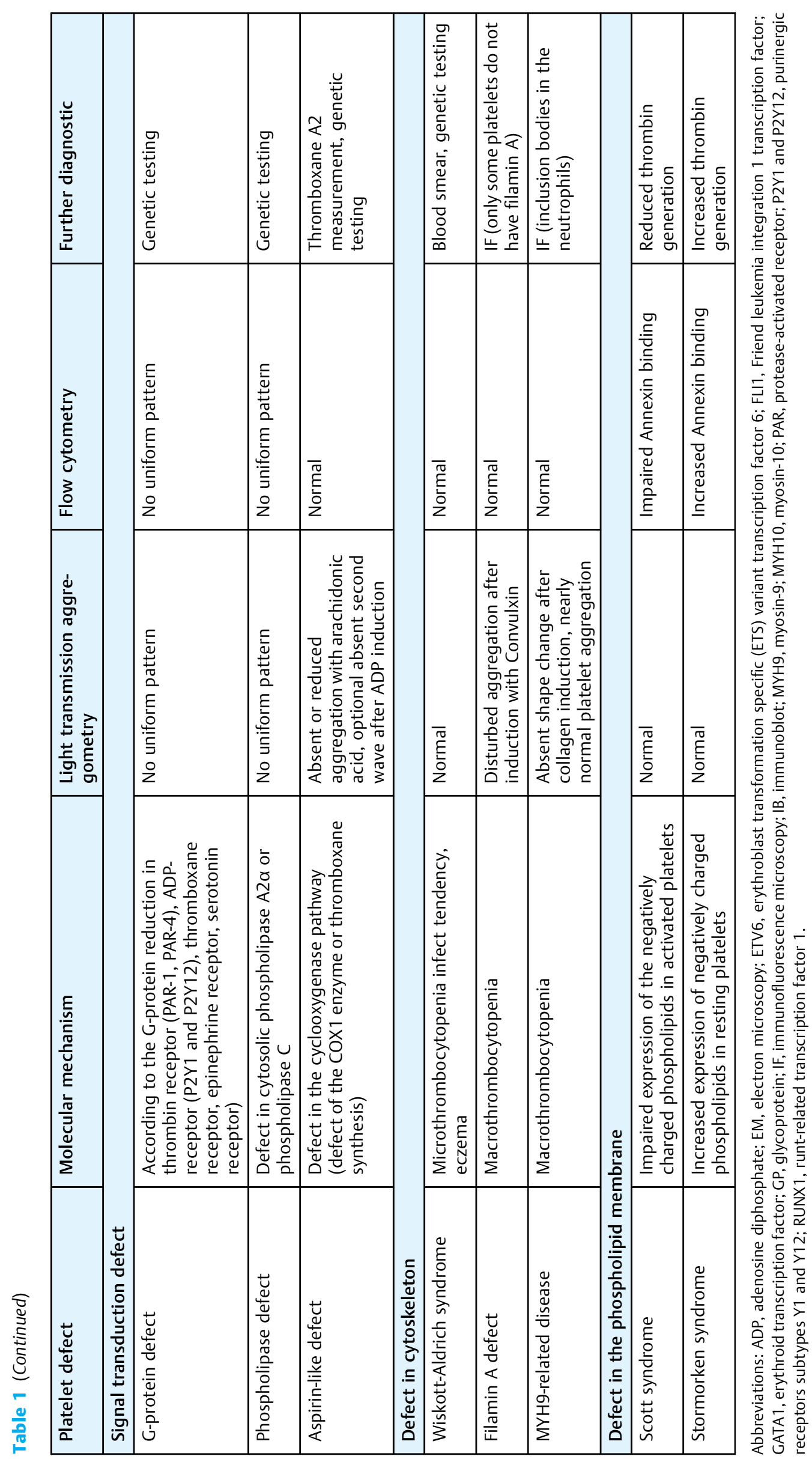




\section{A giant platelets}

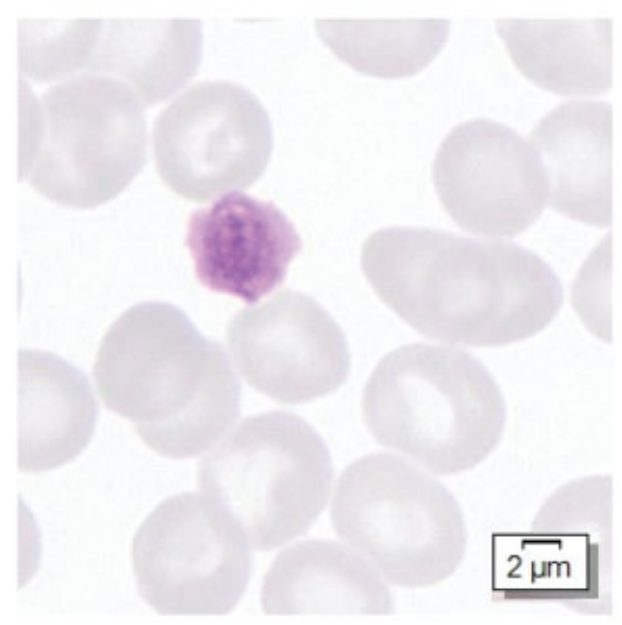

C aggregates

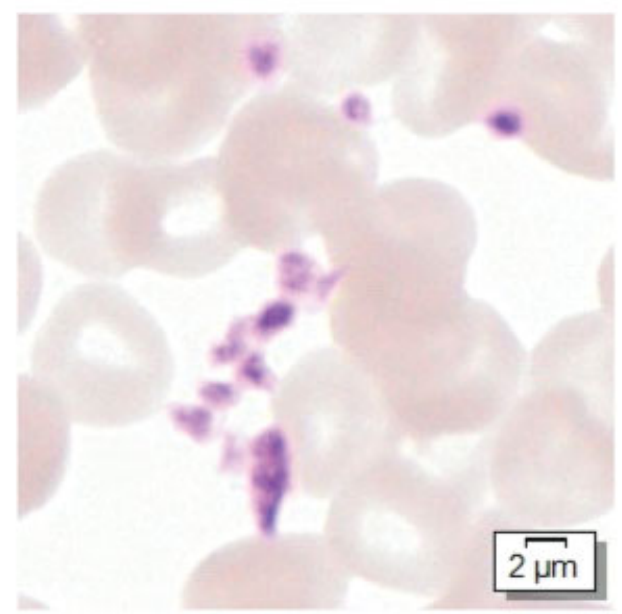

B normal size

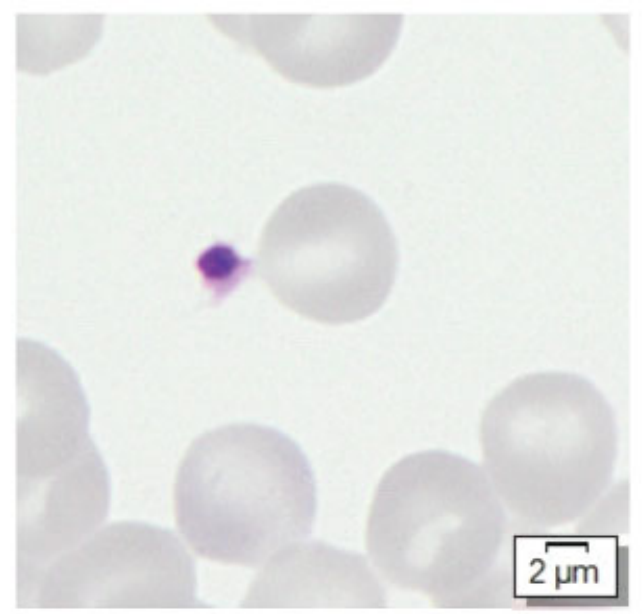

D grey platelets

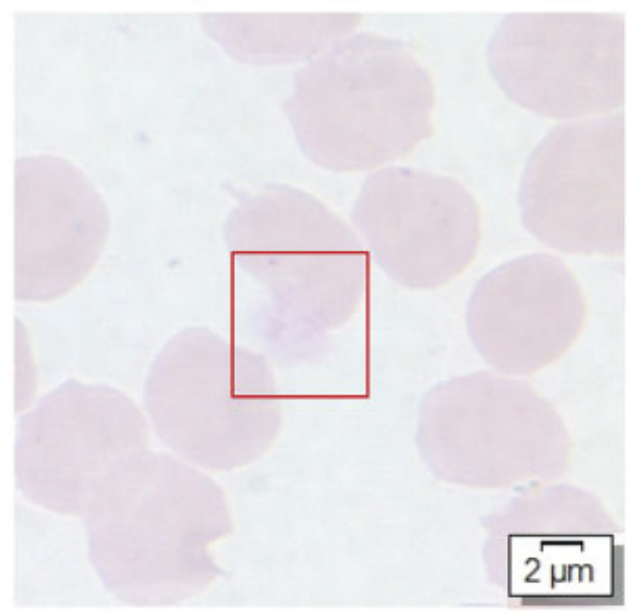

Fig. 1 Light microscopy as the first step of morphological evaluation. (A) Typical light microscopy of a patient with giant platelets. Platelets are nearly as large as a normal red blood cell. (B) Normal size platelet from a healthy control. (C) An anticoagulant-related false low platelet count as a result of a spontaneous aggregate formation in vitro. (D) Patients with gray platelet syndrome have enlarged, but not giant platelets. They show a gray appearance in Giemsa staining.

(TEG; Haemonetics Corp., Boston, Massachusetts, United States), rotational thromboelastometry (ROTEM; Instrumentation Laboratory, Bedford, Massachusetts, United States), and the ClotPro (Haemonetics Corp.) characterize in different parameters the clot initiation (coagulation time, clot formation time), the clot strength and stiffness (maximal clot firmness) and clot resolution/lysis (maximal lysis). Functionally intact platelets and fibrinogen are required for the development of a stable viscoelastic thrombus. While viscoelastometry is not a sensitive method for the detection of platelet disorders, it still plays a role in perioperative and trauma management as an indicator of severe thrombocytopenia and/or extensive platelet function inhibition. ${ }^{25,26}$

\section{Whole-Blood Impedance Aggregometry}

The impedance-based electrode aggregometry allows the assessment of platelet function in a point-of-care setting in hirudin-anticoagulated whole blood without further sample processing. The platelet aggregation is measured by two electronic sensors and the area under the curve is calculated separately by each sensor. It requires a minimal technical knowledge of the operator. It was introduced as a reproducible and sensitive method for the evaluation of antiplatelet drug therapy and assessment of platelet function. ${ }^{27}$

However, whole blood impedance aggregometry was not able to discriminate between patients with and without platelet function defects detected by light transmission aggregometry (LTA) and is therefore not sensitive enough to detect mild platelet function defects. ${ }^{22}$

In addition, large, randomized trials have failed to demonstrate superiority of platelet function monitoring to adjust individually the dual-antiplatelet therapy in cardiovascular disease. ${ }^{28-30}$ This led the European Society of Cardiology to recommend that whole blood impedance aggregometry may 


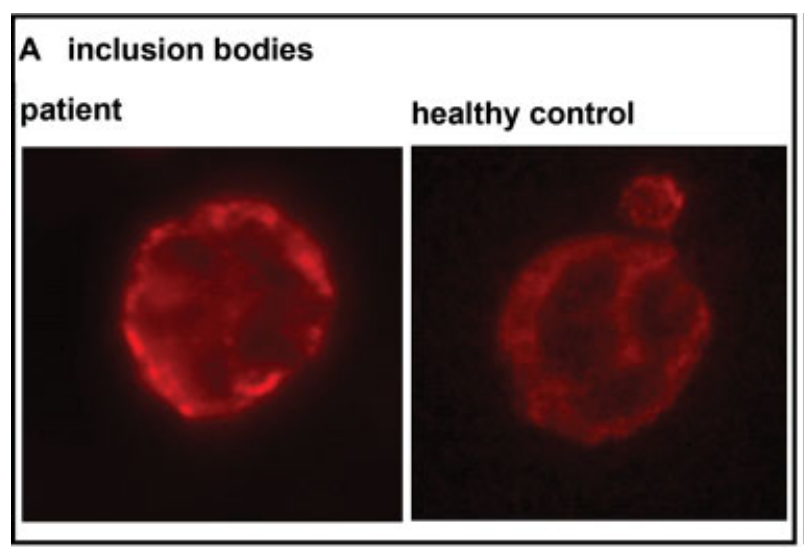

\section{B granule content \\ patient}

healthy control

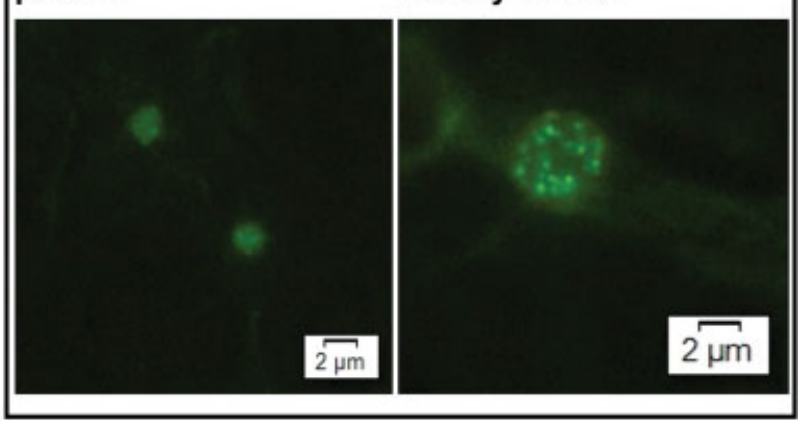

D cytosceleton defect (B1-tubulin)

C receptor defect (IbIX)

patient

healthy control
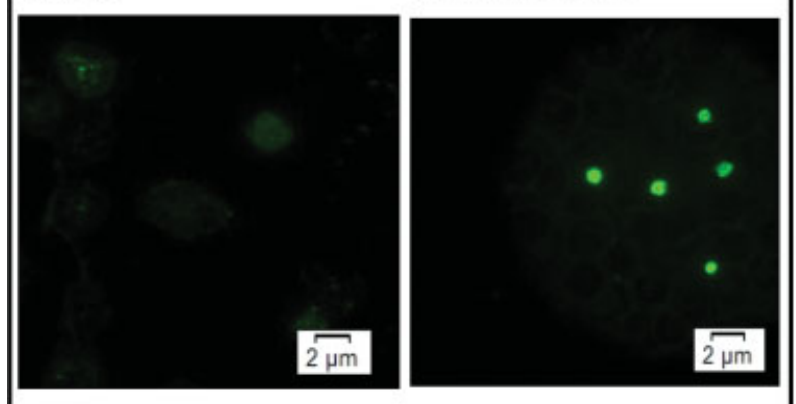

healthy control

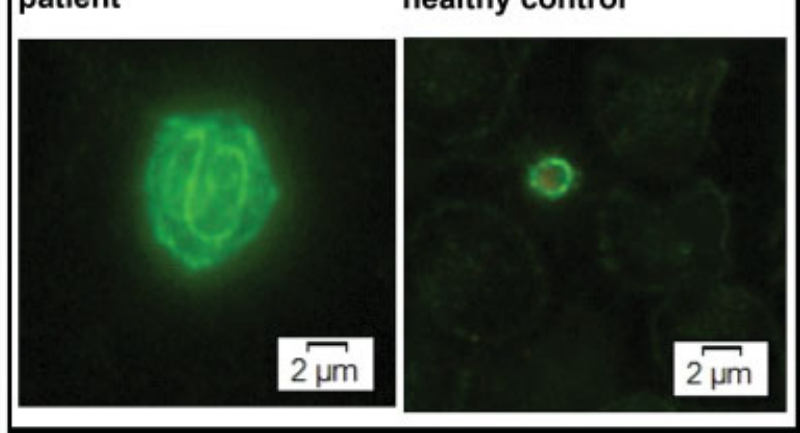

Fig. 2 Representative immunofluorescence staining of patients and healthy controls with different diseases. (A) Immunofluorescence staining of a patient with MYH9-related disease. Nonmuscular myosin heavy chain IIA (NMMHC-IIA) is stained with an anti-monoclonal antibody. Neutrophils show typical clusters. (B) Representative immunofluorescence microscopy of a patient with storage pool disease. CD63 is absent in this patient. (C) Enlarged platelets of a patient with Bernard-Soulier syndrome. (D) $\beta 1$-Tubulin defects are associated with enlarged platelets and alteration of the $\beta 1$ tubulin distribution. It resembles a ball of wool. In the healthy control, a typical $\beta 1$-tubulin ring is visible.

be considered only for specific situations such as in patients with recurrent adverse bleeding events or recurrent thromboembolic events. In these cases, the results may change the treatment strategy. ${ }^{31}$

Light Transmission Aggregometry According to Born The LTA is the gold standard in platelet function testing and was first described by Born in 1962 (-Fig. 3A-D). ${ }^{32}$ It records changes in light transmission caused by agonist-induced platelet aggregation in platelet-rich plasma (PRP). It is fully dependent on fibrinogen-induced platelet aggregation via glycoprotein (GP) IIb-IIla or von Willebrand-dependent platelet agglutination via the GP Ib-IX-V receptor. It is recommended as a first-line diagnostic approach by the ISTH and several surveys and recommendations aim to increase standardization of the procedure. ${ }^{3-5,33,34}$ Using different agonists in different concentrations allows the differentiation and characterization of specific platelet defects.

According to the ISTH, recommended agonists are epinephrine ( $\alpha 2 \mathrm{~A}$ receptor) in a concentration of $5 \mu \mathrm{M}$ and use of higher concentrations in case of impaired platelet function. The diagnostic panel should also include ADP (purinergic receptors subtype $\mathrm{Y} 1$ and $\mathrm{Y} 12, \mathrm{P} 2 \mathrm{Y} 1$, and $\mathrm{P} 2 \mathrm{Y} 12$ receptor) with the lowest concentration of $2 \mathrm{mM}$ and Horn Collagen (GP Ia-Ila and GP VI receptor, minimum concentration of $2 \mathrm{mg} / \mathrm{mL}$ ), thrombin receptor activating peptide- 6 activating the protease-activated receptor 1 in a concentration of 10 $\mu \mathrm{M}$. To detect aspirin intake, the additional use of the thromboxane A2-mimetic U46619 ( $1 \mu \mathrm{M})$ and the use of arachidonic acid ( $1 \mathrm{mM}$, and higher concentration in case of impaired function) can be considered. Finally, the use of the agglutination agent Ristocetin $(1.2 \mathrm{mg} / \mathrm{mL}, 0.5-0.7 \mathrm{mg} / \mathrm{mL}$ ) detects the von Willebrand-mediated agglutination of platelets via the GP Ib-IX-V receptor. ${ }^{5}$

The platelet aggregation curve should be evaluated for the presence of shape change, length of the lag phase, slope of aggregation, maximal amplitude or \% aggregation at the end of the monitoring period, disaggregation, and the presence of a "secondary wave" induced by epinephrine. ${ }^{5}$ For example, for the detection of defects in the granule release, the use of a low agonist concentration is important (missing amplification of the agonist-induced $\mathrm{ADP} /$ adenosine triphosphate [ATP] release from the granules as seen in higher agonist concentrations). Defects in the cytoskeleton can cause an absence of shape change with otherwise nearly normal platelet function (missing shape change in giant platelets from patients with MYH9-related diseases). Defects in the GP IIb-IIIa receptor induces the complete absence of platelet aggregation with normal agglutination induced by Ristocetin via the GP Ib-IX receptor ( - Fig. 4A).

LTA usually requires a normal platelet count (150$600 \times 10^{9} / \mathrm{L}$ ) in $\mathrm{PRP},{ }^{5}$ but optional control samples adjusted 


\section{A collagen}

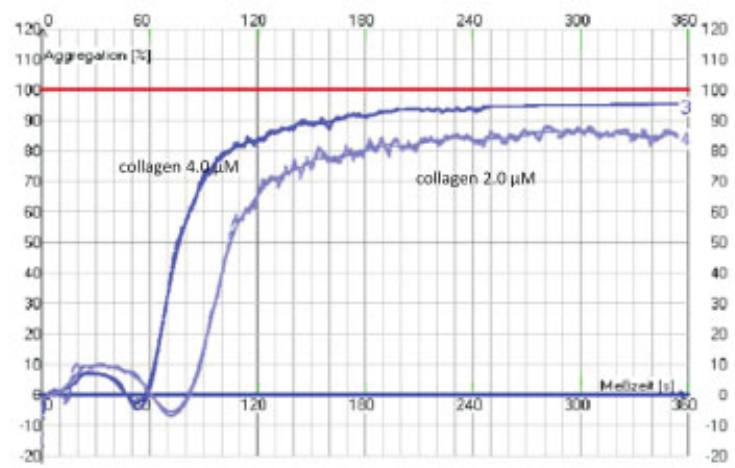

\section{ADP}

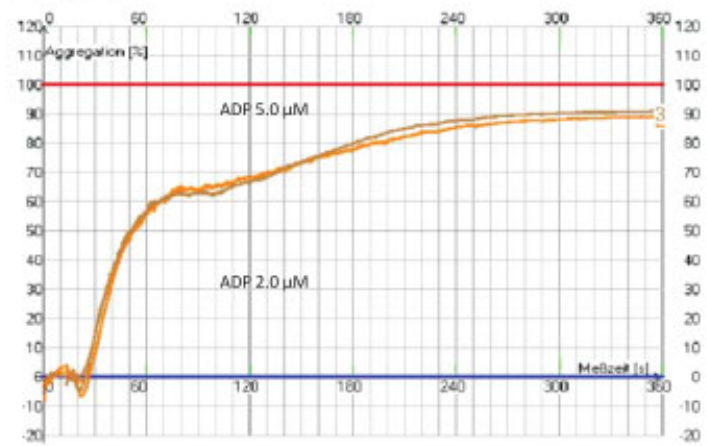

\section{B arachidonic acid}

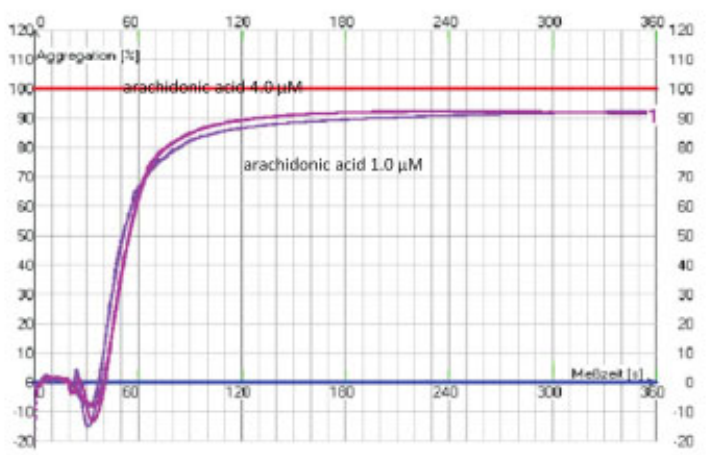

\section{D epinephrine}

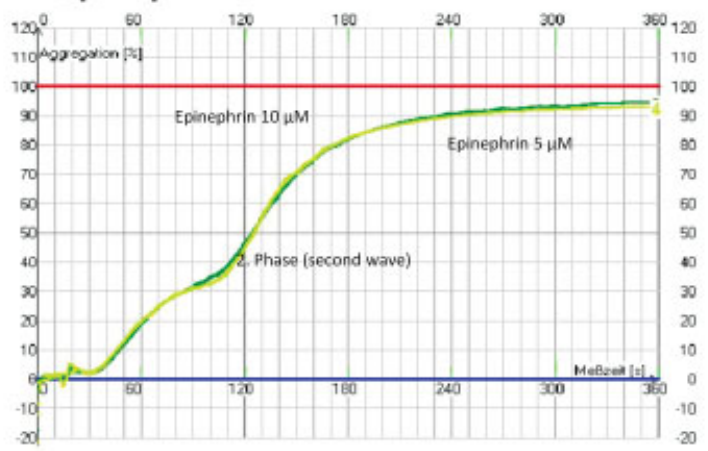

Fig. 3 Classical light transmission aggregometry in a healthy control. (A) Representative normal tracings of collagen with typical shape change. (B) Arachidonic acid is converted into thromboxane A2 in platelets. In patients with aspirin intake or with defects in the cyclooxygenase pathway, aggregation response is absent. (C) ADP can bind to the ADP receptor on the surface of platelets. The binding initiates an intracellular calcium release which reflects the first wave of aggregation. The second wave is induced by the release of ADP from delta granules. (D) Epinephrine binds to the $\alpha 2$-adrenergic receptors on the surface of platelets. This induces an inhibition of the adenylyl cyclase and the release of calcium ions. It is also inhibited by aspirin and NSAIDs and the wave is similar to ADP.

with buffer with comparable platelet count may serve as a laboratory reference control to assess platelet function in patients with low platelet count. ${ }^{35}$ Sometimes, especially in patients with enlarged platelets, it is difficult to enrich platelets. In these patients, it can be feasible to generate
PRP with lower centrifugation force or spontaneous sedimentation.

A modification from the LTA is the additional bioluminescent determination of the ATP release via luciferin-luciferase reaction. Oxidative decarboxylation of luciferin in the

\section{A light transmission aggregometry}

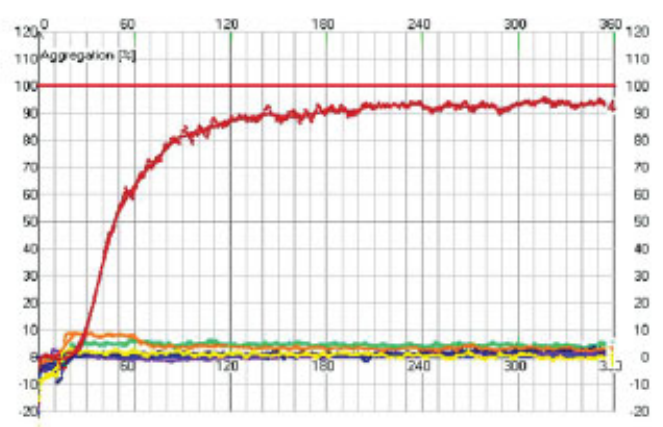

B flow cytometry
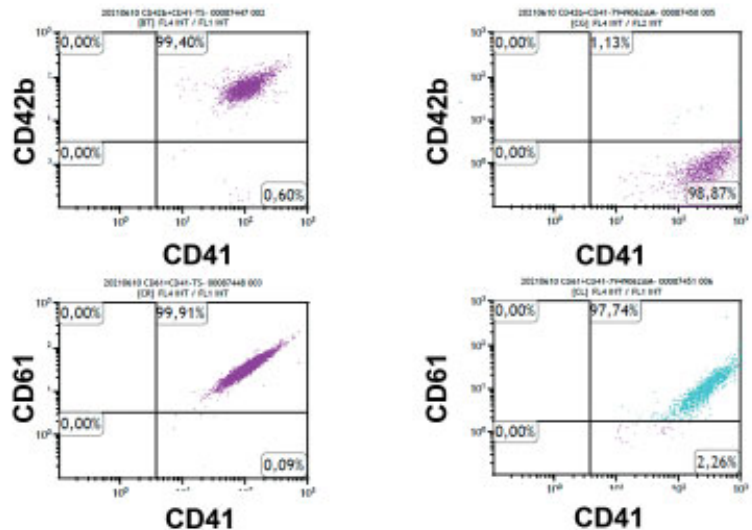

Fig. 4 Representative light transmission aggregometry and flow cytometry of a patient with Glanzmann thrombasthenia. (A) Patients with Glanzmann thrombasthenia show an absent aggregation to all agonists except ristocetin. Ristocetin induces an agglutination through von Willebrand factor and the GP Ib-IX receptor. (B) Flow cytometry of platelets of this patient showed a normal binding to CD61 with absent activity with CD41. 
presence of ATP results in a light emission which can be detected. It is evaluated with whole blood and PRP for the detection of delta-granule defects. ${ }^{36}$

\section{Flow Cytometry}

Investigation of platelet function defects via flow cytometry can evaluate GP expression and granule release. Via fluorescence-labeled antibodies, GP receptors are detected like the collagen receptor GP Ia-IIa ( $\alpha 2 \beta 1$, CD $49 / C D 29)$, the GP IIbIIIa receptor (GP IIb-IIIa $=\alpha I I b \beta 3, C D 41 / 61)$, and the GP IbIX-V receptor (GP Ib $\alpha$ [CD42b], GP Ib $\beta$ [CD42c], GP IX [CD42a], and GP V [CD42d]; - Fig. 4 B).

Furthermore, flow cytometry is able to detect several aspects of platelet activation status in response to a variety of platelet agonists. Alpha granule release, for example, can be detected by P-selectin and thrombospondin expression. ${ }^{37,38} \mathrm{CD} 40 \mathrm{~L}$ release can be measured as a marker for activated platelets. ${ }^{39}$ Agonist-induced dense granule and lysosome exocytosis enable the detection of mepacrine uptake (dense granule), ${ }^{40,41}$ CD63 expression (dense granules, granulolysin), ${ }^{42,43}$ Lamp 2 (dense granules and lysosomes), ${ }^{44}$ and Lamp 1 (lysosomes). ${ }^{45}$

Changes in intracellular calcium levels via Fluo- $3,{ }^{46}$ or measurement of phosphorylation events like vasodilatorstimulated phosphoprotein or serine-threonine kinase signaling, also enable the assessment of platelet activation status even for a small sample size and in case of thrombocytopenia. ${ }^{47-49}$

Flow cytometry is not used solely for the detection of GP expression and platelet activation status. Another approach is the detection of procoagulant platelets, which enhance thromboembolic events via increased phosphatidylserine expression. ${ }^{50,51}$

\section{Immunoblot}

The immunoblot is an immunodetection of blotted proteins by antibodies, after protein extraction from the platelets, electrophoresis, and transfer of the extracted proteins to a gel. It can produce qualitative and semiquantitative data about the protein of interest in platelets. Immunoblot is an important confirmatory step in the classification of new platelet diseases. It is not a routine method and reserved for research purposes.

\section{Genetic Testing}

Genetic testing is an important diagnostic tool in the identification of inherited platelet disorders. Claire Lentaigne described 51 causative genes to be responsible for inherited platelet disorders. ${ }^{52}$ Genetic testing can serve as confirmation of the results of morphologic and functional testing and, in some cases, allow for better clinical decision making. For example, in MYH9-related diseases, several mutations have been described as hotspot regions for nonhematologic renal impairment. ${ }^{53}$ In these cases, the early administration of angiotensin II receptor type 1 (AT1) antagonists may have beneficial effects. ${ }^{54}$

Some platelet syndromes are also associated with an increased risk of malignancies, ${ }^{55}$ and require a detailed genetic counseling for the patient. The patient should be well informed to carefully decide whether she or he wishes to receive genetic information or not and that this test result might include information about the risk of future illness like malignancies.

Despite the advances in functional testing during the years, the diagnosis of platelet function defects remains challenging. It requires a good collaboration between the clinician and the laboratories. Multiple assays are necessary to allow narrowing down the diagnosis in platelet function defects. A good characterization of platelet function defects should include bleeding history in a standardized bleeding assessment tool, platelet morphology by microscopy (Giemsa staining and immunofluorescence), as well as functional testing. An unexpected test result should always be repeated and all consumed drugs and their drug interactions should be taken into consideration in unexpected bleeding situation. This assessment will also improve the genetic testing, as many causative genetic defects are still unknown and good characterization is needed to prove new genes and unknown variants as a causative reason for special defects.

In conclusion, a specialized diagnostic approach is important to identify the platelet function defects in patients with a bleeding tendency. With a better characterization of the defects in platelets, it offers a new opportunity for individualized medicine in patients with acquired defects and to avoid unnecessary treatment in patients with inherited platelet defects.

\section{Conflicts of Interest}

K.A. received research grant from the German Red Cross. T. B. reports receiving honorarium for a scientific talk from Aspen Germany, CSL Behring, Stago gGmbH German, and research grants from the German Society of Research, the German Society for Transfusion Medicine, and German Red Cross.

\section{References}

1 Orsini S, Noris P, Bury L, et al; European Hematology Association Scientific Working Group (EHA-SWG) on Thrombocytopenias and Platelet Function Disorders. Bleeding risk of surgery and its prevention in patients with inherited platelet disorders. Haematologica 2017;102(07):1192-1203

2 Scharf RE. Drugs that affect platelet function. Semin Thromb Hemost 2012;38(08):865-883

3 Cattaneo M, Hayward CP, Moffat KA, Pugliano MT, Liu Y, Michelson AD. Results of a worldwide survey on the assessment of platelet function by light transmission aggregometry: a report from the platelet physiology subcommittee of the SSC of the ISTH. J Thromb Haemost 2009;7(06):1029

4 Althaus K, Zieger B, Bakchoul T, Jurk KTHROMKID-Plus Studiengruppe der Gesellschaft für Thrombose- und Hämostaseforschung (GTH) und der Gesellschaft für Pädiatrische Onkologie und Hämatologie $(\mathrm{GPOH})$ Standardization of light transmission aggregometry for diagnosis of platelet disorders: an inter-laboratory external quality assessment. Thromb Haemost 2019;119 (07):1154-1161

5 Cattaneo M, Cerletti C, Harrison P, et al. Recommendations for the standardization of light transmission aggregometry: a consensus of the working party from the platelet physiology subcommittee 
of SSC/ISTH. J Thromb Haemost 2013;10(Apr);. Doi: 10.1111/ jth.12231

6 The British Society for Haematology BCSH Haemostasis and Thrombosis Task Force. Guidelines on platelet function testing. J Clin Pathol 1988;41(12):1322-1330

7 Konkle BA. Acquired disorders of platelet function. Hematology (Am Soc Hematol Educ Program) 2011;2011:391-396

8 Olas B. Dietary supplements with antiplatelet activity: a solution for everyone? Adv Nutr 2018;9(01):51-57

9 Pecci A, Balduini CL. Inherited thrombocytopenias: an updated guide for clinicians. Blood Rev 2021;48:100784

10 Rodeghiero F, Tosetto A, Abshire T, et al; ISTH/SSC Joint VWF and Perinatal/Pediatric Hemostasis Subcommittees Working Group. ISTH/SSC bleeding assessment tool: a standardized questionnaire and a proposal for a new bleeding score for inherited bleeding disorders. J Thromb Haemost 2010;8(09):2063-2065

11 Rodeghiero F, Pabinger I, Ragni M, et al. Fundamentals for a systematic approach to mild and moderate inherited bleeding disorders: an EHA consensus report. HemaSphere 2019;3(04): e286

12 Vries MJ, van der Meijden PE, Kuiper GJ, et al. Preoperative screening for bleeding disorders: a comprehensive laboratory assessment of clinical practice. Res Pract Thromb Haemost 2018;2(04):767-777

13 Ambaglio C, Zane F, Russo MC, et al. Preoperative bleeding risk assessment with ISTH-BAT and laboratory tests in patients undergoing elective surgery: a prospective cohort study. Haemophilia 2021;27(05):717-723

14 Koscielny J, Ziemer S, Radtke H, et al. A practical concept for preoperative identification of patients with impaired primary hemostasis. Clin Appl Thromb Hemost 2004;10(03):195-204

15 Althaus K, Greinacher A. MYH9-related platelet disorders. Semin Thromb Hemost 2009;35(02):189-203

16 Bury L, Megy K, Stephens JC, et al. Next-generation sequencing for the diagnosis of MYH9-RD: predicting pathogenic variants. Hum Mutat 2020;41(01):277-290

17 Greinacher A, Pecci A, Kunishima S, et al. Diagnosis of inherited platelet disorders on a blood smear: a tool to facilitate worldwide diagnosis of platelet disorders. J Thromb Haemost 2017;15(07): 1511-1521

18 Mielke CH Jr, Kaneshiro MM, Maher IA, Weiner JM, Rapaport SI. The standardized normal Ivy bleeding time and its prolongation by aspirin. Blood 1969;34(02):204-215

19 Peterson P, Hayes TE, Arkin CF, et al. The preoperative bleeding time test lacks clinical benefit: College of American Pathologists' and American Society of Clinical Pathologists' position article. Arch Surg 1998;133(02):134-139

20 Gewirtz AS, Kottke-Marchant K, Miller ML. The preoperative bleeding time test: assessing its clinical usefulness. Cleve Clin J Med 1995;62(06):379-382

21 Franchini M. The platelet function analyzer (PFA-100): an update on its clinical use. Clin Lab 2005;51(7-8):367-372

22 Moenen FCJI, Vries MJA, Nelemans PJ, et al. Screening for platelet function disorders with multiplate and platelet function analyzer. Platelets 2019;30(01):81-87

23 Ardillon L, Ternisien C, Fouassier M, et al. Platelet function analyser (PFA-100) results and von Willebrand factor deficiency: a 16-year 'real-world' experience. Haemophilia 2015;21(05): 646-652

24 Gresele PSubcommittee on Platelet Physiology of the International Society on Thrombosis and Hemostasis. Diagnosis of inherited platelet function disorders: guidance from the SSC of the ISTH. J Thromb Haemost 2015;13(02):314-322

25 Bowbrick VA, Mikhailidis DP, Stansby G. Value of thromboelastography in the assessment of platelet function. Clin Appl Thromb Hemost 2003;9(02):137-142

26 Ranucci M, Baryshnikova E. Sensitivity of viscoelastic tests to platelet function. J Clin Med 2020;9(01):E189
27 Tóth O, Calatzis A, Penz S, Losonczy H, Siess W. Multiple electrode aggregometry: a new device to measure platelet aggregation in whole blood. Thromb Haemost 2006;96(06):781-788

28 Collet JP, Cuisset T, Rangé G, et al; ARCTIC Investigators. Bedside monitoring to adjust antiplatelet therapy for coronary stenting. $\mathrm{N}$ Engl J Med 2012;367(22):2100-2109

29 Trenk D, Stone GW, Gawaz M, et al. A randomized trial of prasugrel versus clopidogrel in patients with high platelet reactivity on clopidogrel after elective percutaneous coronary intervention with implantation of drug-eluting stents: results of the TRIGGER-PCI (Testing Platelet Reactivity In Patients Undergoing Elective Stent Placement on Clopidogrel to Guide Alternative Therapy With Prasugrel) study. J Am Coll Cardiol 2012;59 (24):2159-2164

30 Price MJ, Berger PB, Teirstein PS, et al; GRAVITAS Investigators. Standard- vs high-dose clopidogrel based on platelet function testing after percutaneous coronary intervention: the GRAVITAS randomized trial. JAMA 2011;305(11):1097-1105

31 Valgimigli M, Bueno H, Byrne RA, et al; ESC Scientific Document Group ESC Committee for Practice Guidelines (CPG) ESC National Cardiac Societies. 2017 ESC focused update on dual antiplatelet therapy in coronary artery disease developed in collaboration with EACTS: The Task Force for dual antiplatelet therapy in coronary artery disease of the European Society of Cardiology (ESC) and of the European Association for Cardio-Thoracic Surgery (EACTS). Eur Heart J 2018;39(03):213-260

32 Born GV. Aggregation of blood platelets by adenosine diphosphate and its reversal. Nature 1962;194:927-929

33 Hayward CP, Moffat KA, Raby A, et al. Development of North American consensus guidelines for medical laboratories that perform and interpret platelet function testing using light transmission aggregometry. Am J Clin Pathol 2010;134(06):955-963

34 Gresele P, Harrison P, Bury L, et al. Diagnosis of suspected inherited platelet function disorders: results of a worldwide survey. J Thromb Haemost 2014;12(09):1562-1569

35 Cattaneo M, Lecchi A, Zighetti ML, Lussana F. Platelet aggregation studies: autologous platelet-poor plasma inhibits platelet aggregation when added to platelet-rich plasma to normalize platelet count. Haematologica 2007;92(05):694-697

36 Cattaneo M. Light transmission aggregometry and ATP release for the diagnostic assessment of platelet function. Semin Thromb Hemost 2009;35(02):158-167

37 Carmody MW, Ault KA, Mitchell JG, Rote NS, Ng AK. Production of monoclonal antibodies specific for platelet activation antigens and their use in evaluating platelet function. Hybridoma 1990;9 (06):631-641

38 Aiken ML, Ginsberg MH, Plow EF. Mechanisms for expression of thrombospondin on the platelet cell surface. Semin Thromb Hemost 1987;13(03):307-316

39 Henn V, Slupsky JR, Gräfe M, et al. CD40 ligand on activated platelets triggers an inflammatory reaction of endothelial cells. Nature 1998;391(6667):591-594

40 Wall JE, Buijs-Wilts M, Arnold JT, et al. A flow cytometric assay using mepacrine for study of uptake and release of platelet dense granule contents. Br J Haematol 1995;89(02):380-385

41 Manukjan G, Eilenberger J, Andres O, Schambeck C, Eber S, Schulze H. Functional classification of paediatric patients with non-syndromic delta-storage pool deficiency. Hamostaseologie 2019;39(04):383-391

42 Nieuwenhuis HK, van Oosterhout JJ, Rozemuller E, van Iwaarden F, Sixma JJ. Studies with a monoclonal antibody against activated platelets: evidence that a secreted 53,000-molecular weight lysosome-like granule protein is exposed on the surface of activated platelets in the circulation. Blood 1987;70(03):838-845

43 Nishibori M, Cham B, McNicol A, Shalev A, Jain N, Gerrard JM. The protein $C D 63$ is in platelet dense granules, is deficient in a patient with Hermansky-Pudlak syndrome, and appears identical to granulophysin. J Clin Invest 1993;91(04):1775-1782 
44 Israels SJ, McMillan EM, Robertson C, Singhory S, McNicol A. The lysosomal granule membrane protein, LAMP-2, is also present in platelet dense granule membranes. Thromb Haemost 1996;75 (04):623-629

45 Febbraio M, Silverstein RL. Identification and characterization of LAMP-1 as an activation-dependent platelet surface glycoprotein. J Biol Chem 1990;265(30):18531-18537

46 Aliotta A, Bertaggia Calderara D, Alberio L. Flow cytometric monitoring of dynamic cytosolic calcium, sodium, and potassium fluxes following platelet activation. Cytometry A 2020;97(09):933-944

47 Althaus K, Wagner M, Marini I, Bakchoul T, Pelzl L. Flow cytometric assessment of AKT signaling in platelet activation: an alternative diagnostic tool for small volumes of blood. Hamostaseologie 2020;40(S 01)S21-S25

48 Abbasian N, Millington-Burgess SL, Chabra S, Malcor JD, Harper MT. Supramaximal calcium signaling triggers procoagulant platelet formation. Blood Adv 2020;4(01):154-164

49 Walter U, Geiger J, Haffner C, et al. Platelet-vessel wall interactions, focal adhesions, and the mechanism of action of endothelial factors. Agents Actions Suppl 1995;45:255-268

50 Althaus K, Marini I, Zlamal J, et al. Antibody-induced procoagulant platelets in severe COVID-19 infection. Blood 2021;137(08): 1061-1071
51 Althaus K, Möller P, Uzun G, et al. Antibody-mediated procoagulant platelets in SARS-CoV-2-vaccination associated immune thrombotic thrombocytopenia. Haematologica 2021;106(08): 2170-2179

52 Lentaigne C, Freson K, Laffan MA, Turro E, Ouwehand WHBRIDGEBPD Consortium and the ThromboGenomics Consortium. Inherited platelet disorders: toward DNA-based diagnosis. Blood 2016; 127(23):2814-2823

53 Pecci A, Panza E, Pujol-Moix N, et al. Position of nonmuscle myosin heavy chain IIA (NMMHC-IIA) mutations predicts the natural history of MYH9-related disease. Hum Mutat 2008;29(03): 409-417

54 Tanaka M, Miki S, Saita $\mathrm{H}$, et al. Renin-angiotensin system blockade therapy for early renal involvement in MYH9-related disease with an E1841K mutation. Intern Med 2019;58(20): 2983-2988

55 Porter CC. Germ line mutations associated with leukemias. Hematology (Am Soc Hematol Educ Program) 2016;2016(01): 302-308

56 Althaus K, Wagner M, Bakchoul T. Diagnose der Thrombozytenfunktionsstörungen - eine Herausforderung im Labor. [The diagnosis of platelet function disorders - a challenge in the laboratory.]. Transfusionsmedizin 2019;9(02):96-108 